But though the animal waxes fat and regains the full vigour of health and strength, the enlarged condition of the maxillæ is a permanent change. I do not know what the effect of re-introduction into the clamp District of $\mathrm{O}$. would be.

\title{
A BRIEF COMPARISON OF THE VARIOUS METHODS WHEREBY HORSES ARE CASTRATED.
}

By H. Caulton ReEks, F.R.C.V.S., Spalding.

BEFORE commencing what I have to say on this subject, I beg to offer a few words of apology to Professor Hobday for taking as my text the title of a paper recently contributed by him to the Southern Counties Veterinary Medical Association. In this paper he says:-

"What I propose to lay before you for discussion are certain conclusions arrived at as the result of observations made upon between 350 to 400 horses with the various kinds of instruments now in general use. I shall ask each one of you to say what instruments you have given a fair trial, and what are the ultimate conclusions you have come to."

That, I take it, is offering a fair and open field for anyone who has read his paper to step in and state his experiences. At any rate, that is my excuse, and Professor Hobday will, I am sure, take anything I have to say in the light of fair and honest criticism.

Preparatory to noticing any special method of operation, it will be as well to first consider what are the means that Nature herself takes to prevent serious and fatal hæmorrhage. It is necessary to do this in order to bring a full and unbiassed judgment to bear on our consideration of surgical methods. Nature's efforts to bring about a natural hæmostasis fall distinctly under two headings, viz., TEMPORARI means and PERMANENT ones.

The Temporary Means consist in :-

I. The coagulation of the blood in and around the wounded vessel. This, of all the means adopted by Nature, is by far the most important. Did not the blood possess this special property of coagulation, it would continue to drain away from any cut vessel, no matter how small, until death ensued. Although this coagulation is of itself sufficient to arrest the arterial flow in vessels of a certain size, Nature beneficently makes this further provision. As the blood flows there comes about a greater degree of coagulability, owing to alterations in the blood itself.

2. The lessening in force of the heart's action as the patient becomes faint plays a very considerable part in the arrest of the blood flow. As every one may see, the forcible spurt from the mouth of a divided artery with each contraction of the ventricle opposes strongly any formation of a blood-clot around and within the cut vessel. With increasing faintness the heart's impulse becomes weaker and weaker, until the spurt is almost imperceptible. This gives the blood time to form an adherent coagulum in the vicinity of the wound, and points 
out the inadvisability of too quickly administering stimulants to a patient in a fainting condition from hæmorrhage.

3. The changes produced in and around the vessel itself are those which really bring about the final arrest of the bleeding. When an artery is cut across the contraction of the longitudinal fibres of the inner coat causes it to retract within its sheath; at the same time its orifice becomes narrowed by the contraction of the circular muscle fibres of the middle coat. This contraction of the two inner coats leaves the outer sheath with rough and uneven edges. The blood flowing over these roughened edges becomes entangled, and tends to coagulate upon them, the coagulation being assisted, as we have already seen, by the increased coagulability of the blood as it flows and the diminution in force of the heart beats.

By these means a coagulum is formed both within and without the sheath of the artery, but external to the middle coats of the vessel. The contracted and roughened ends of the sheath act somewhat the part of a clamp in retaining the coagulum next to the divided end of the artery.

The part which this external coagulum, as it is called, plays in the arrest of the bleeding is supplemented by the formation of an internal coagulum.

As the open end of the artery becomes occluded both by its own contraction and the formation of the external coagulum, the blood escapes less freely, until at last the flow stops altogether. Coagulation then takes place inside the vessel, and an internal coagulum is formed which undoubtedly acts largely as a buffer in breaking the force of the blood flow against the external clot.

Permanent closure of the vessel then takes place by means identical with those which effect the healing of wounds by first intention. The inflammatory processes following bring about gradual removal of the coagula, and the formation of fibrous tissue completes the healing.

Briefly considering these different methods by which natural hæmostasis is effected, we notice that rest of the wounded part must be strictly enforced if a perfect coagulum and the other necessary changes are to be obtained. As with our patients it is impossible to order complete quietness and rest of the wounded member, it is evident that too much reliance cannot be placed on nature's method of working, and that we must do all in our power to help and bring about the desired result. Applying my last few remarks to the subject of castration, I have noticed that some animals after the operation will, if there be extensive bleeding, instinctively stand quiet, as though they knew full well the danger of movement. Others, on the contrary, are equally unstable, and not until they are in the last stages of collapse do they remain anything like still.

Speaking, as I am now, of extensive hæmorrhage, we must remember that any method of operation in which that is likely to occur with more frequency than in others should be at once removed from our list. Not only is there the anxiety and trouble at the time of operation to consider, but, in addition, it must be borne in mind that not always does the bad effect of a large loss of blood end with the successful closure of the artery. In some cases the health becomes permanently injured and a state of chronic anæmia induced, which, notwithstanding the administration of iron and tonics, may continue 
through life. Add to that the fact that large accumulations of blood in the scrotum are dangerous, in that they may form the startingpoint for an abscess, and I have said enough. It must not be forgotten, either, that the spermatic artery springs directly from the posterior aorta, and that, owing to the strong blood-flow within it, nature requires to be largely helped by man when this vessel is divided.

Having noted shortly what help we shall receive from nature, we may now carefully review a few of the modes of castration in most general use at this time. What we must particularly inquire is: Is the method we are adopting in accordance with what nature would demand, and are we assisting her to bring about the desired result or are we dragging on her heels?

\section{SURGICAL TREATMENT OF ARTERIAL HAMORRHAGE IN CASTRATION.}

I. Pressure.-Our best example of this is to be found in the oldfashioned and still safe clams of wood or other material. Whenever pressure is used to stay arterial haemorrhage it must, to be of any use, be applied with sufficient force to arrest the flow of blood through the wounded vessel. It must necessarily also empty all the surrounding capillaries and veins, and render the part absolutely bloodless. Since we know that the effect of this, if kept up long enough, will be to cause death of the part, it follows that the shorter time within reason pressure is employed the better.

If not on long enough to cause death of the part, what happens when the clams are removed is that all the phenomena of inflammation are commenced at that point, and by its means the part is brought again to the normal. The excessive and prolonged use of pressure would undoubtedly be to cause sloughing. It is evident. then, that pressure should be persisted in only so long as is necessary to arrest the flow of blood, and not for a single hour longer should its continuance be advised. Experience has shown that in the horse twelve to twenty-four hours is not too long, and that by that time bleeding is effectually arrested. That its use is followed by desirable results the long continuance of the clams in favour from the earliest times until now is sufficient evidence. If properly sterilised, their use is quite in accordance with what nature requires of us. They close the cut end of the artery until an internal coagulum has formed; they effectually close the vessel before even a drop of blood has been allowed to escape into the scrotum; and, if not left on too long, their removal is followed by all the beneficent phenomena of a restorng inflammation.

2. Cauterisation.-This, in human surgery, was practised largely by the ancients and in the Middle Ages. Now it is seldom employed. Yet in some cases, as an undeniable authority assures us, it is of unquestionable utility and superior to any other means we possess. More particularly is it of service when the part from which hæmorrhage is proceeding is soft and spongy and will not hold a ligature, or on the surface of which many spots are bleeding at the same time.

As on the surface of the divided spermatic cord in the horse there 
are several bleeding points, it recommends itself particularly to the veterinary surgeon as a ready and safe means of arresting hæmorrhage when castrating.

It is abundant proof of the intrinsic merit and advisability of this operation over all others that it is the one now in most general use wherever there are horses to be castrated. Also at the Royal Veterinary College, London, it is still used on all animals that are treated for subscribers; all other methods being regarded with a patronising air, and relegated as new-fangled ideas to the background of the Free Clinique. That it is so safe as to almost warrant one in saying it is absolutely so, there can be no denial. For many of the other methods I doubt whether that much may be said.

The actual cautery blocks up the artery by a thick slough or eschar, and the human surgeon is always on his guard lest, when this eschar separates or is cast off on the sixth or eighth day, he may be troubled with secondary hæmorrhage. That this is not the case with veterinary patients I think a long list of castration cases would conclusively prove. For my own part I have never yet seen it.

3. Torsion.-This in veterinary practice is, I believe, resorted to on this one occasion only-the occasion of castration. Properly employed it is of the greatest value. Veterinary practitioners are not yet fully alive to the advantages derived from a careful and judicious use of the artery forceps when operating. By their means a bleeding vessel of large size may be taken up and hæemorrhage securely stopped.

In veterinary castration what is known as limited torsion is practised-i.e., the vessels are held quite close with one pair of forceps or clams while another pair are employed to slowly twist the cord until the whole of its structures have given way. The pressure of the first pair of forceps or clams prevents the ruptured intima and middle coats (which, bye-the-bye, are the first to give way) from turning up properly into the lumen of the vessel. What is known as free torsion, viz., seizing the bleeding vessel itself in a pair of artery forceps, without the medium of a first pair of clams to hold it with, and twisting it in the direction of its long axis, is almost impossible to practise in castrating the horse. That it is the best means of employing torsion there can be no doubt; but that limited torsion is sufficient for our purpose those who have practised it appear to testify.

4. Forci-pressure is a mode of arresting hæmorrhage that consists in seizing the end of a bleeding vessel with a pair of forceps with short blades somewhat deeply serrated, and long scissor handles, provided with a catch to keep them closed. These forceps are fastened with such force as to crush the end of the vessel between the blades. On relaxing their hold after a grip of a few minutes no bleeding takes place. The human surgeon, to make closure of the vessel more certain, gives the forceps a few turns, and so employs free torsion at the same time. Or he may leave the forceps, still gripping the ressel, in the wound for twelve to twenty-four hours, thus conjointly employing pressure and forci-pressure.

I have described forci-pressure at some length for this reason. It will be seen that in reality it is the method in which a good many instruments that have come to the fore in late years do their work. I am alluding to the various forms of crushing emasculators, e.g., the écraseur, in its many different patterns, the emasculator of Webb, 
the original instrument as invented by Blake of Ryde, and such modifications of the Blake instrument as the Huish-Blake and the "Reliance" castrator of Arnold. All these and their like are simply means of employing forci-pressure to arrest the hæmorrhage. True, they sever the cord at the same time; some with a serrated cutting edge and some with a smooth one, but the last act they all perform is the simple one of forci-pressure. $\mathrm{W}^{\top}$ hen used they one and all should be kept for some few minutes tightly closed on the cord; for to effectually stay the hæmorrhage the artery must be crushed. Consequently, it follows that when choosing an instrument one that offers the best crushing surface will turn out to be the most reliable tool. Also, it is wise when purchasing to see that the serrated tecth or roughened blades of the instrument catch the cord before the cutting edge descends on it. I once had one form of instrument in my hands when a sharp-cutting knife severed the cord before the serrated teeth of the instrument had time to grasp it and perform the last stage of the double operation. The cord severed with the knife-like edge slipped back into the scrotum, and a very extensive hamorrhage resulted. My own experience of all these instruments is that they are unreliable, and my reasons for so saying 1 will give later. When time is an object and horse-flesh of little value, they may certainly be relied upon as being convenient and portable. There is no fire to build, they necessitate no second journey, the operation does not last long, and they may be used for either the standing or recumbent mode of operating. That they have advantages with regard to the safety of the animal I feel bound, from what I have seen, to deny.

5. Ligature.-This, I need hardly say, is a means little resorted to by veterinary surgeons for the arrest of hæmorrhage from wounded arteries. A short perusal of the subject in contemporary medical literature is sufficient to point out why this should be so. That it was undoubtedly employed by the later Roman surgeons is evident, but with the decline of surgery in the Dark Ages it fell almost completely into disuse. In $\mathrm{I} 552$ it was re-introduced by one Ambrose Paré, surgeon to the King of France, but so slowly did it make its way that Sharpe, in I76I, found it necessary to formally point out its many advantages over styptics and the cautery, giving as his reason that "it was not as yet universally practised by surgeons residing in the more distant counties of our kingdom."

Seeing that it took two centuries to successfully promulgate the use of this simple and efficacious method of arresting hæmorrhage-the simple tying up of a spouting artery-it is evident there must have been some strong reason. That reason was this: Surgeons of that day were ignorant of nature's means of occluding arteries, and consequently did not know how to best apply a ligature to these vessels or what kind of ligature to employ. To make all safe, they fell into the very errors they should have attempted to avoid. Noticing that such was the case with medical men, I am sure I keep well within bounds when I say that the veterinary surgeon of to-day is not sufficiently acquainted with the correct methods of applying ligatures for the arrest of hamorrhage. It is not largely practised at our veterinary schools, and certainly it is not taught there. But for the fact that Professor Hobday mentioned ligature in his paper, I should not have mentioned it at all. I would, however, beg respectfully to 
point out that if the ligature is to be adopted in veterinary practice, it will necessitate careful and special teaching both orally and practically.

The way in which a ligature should act if properly applied is to rupture the internal and middle coats of the vessel, turning them up so as to form a plug. The external coat it should leave intact. To obtain these results a careful knowledge and understanding of the material to be used will be necessary. It should be neither too thick nor too thin. If too thick, the inner coat of the artery is left untouched, and secondary hamorrhage is to be looked for. If too thin, it eats by a process of ulceration through the vessel wall and comes away with the fibrinous exudate there present after the expiration of some days. Secondary hæmorrhage is again a result, and the artery has to be tied again higher up.

If of unabsorbable material the strictest attention (attention not always possible in veterinary practice) must be paid to antiseptic measures; or the ligature becomes infected with putrefactive matter, acts as a seton, and ulcerates its way out again with secondary bleeding. If of absorbable material the very greatest care must be given to the matter of its preparation, for the act of rendering it aseptic too often will also render it unabsorbable or of such consistence as to make tying it a matter of the greatest difficulty. These with other matters, incluaing the proper tying of knots, are all yet for the veterinary student to learn.

Regarding the application of ligature in castration I have nothing but suggestions to offer. It must be remembered that in the serered spermatic cord of the horse we have several bleeding spots. To apply a ligature in the best possible manner would mean taking up each one of these and tying it separately. That would mean time. A further plan, though to my mind theoretically not so safe, would be to take a needle threaded with the loop end of a doubled piece of silk, pass it through the non-vascular portion of the cord, remove the needle, and then thread the loose ends of the silk each of them through the loop. This drawn up tight and fastened round the cord in a reef-knot will form what I believe is called a Staffordshire knot. After making all safe, excise the testicle. Always, however, where there is likely to be suppuration, ligaturing a vessel is not exactly the safest way in which it may be closed. With the suppuration the ligature will come away, and secondary hæmorrhage is likely to result. Until our antiseptic measures in veterinary practice are much improved 1 am afraid the ligature must be left alone. Personally I think this offers an excellent opportunity for some one with time to spare and means, to do a little original and interesting work of investigation.

I have now considered four of the principal surgical means (now in use) of staying arterial hæmorrhage in castration, viz.:-Pressure, Cauterisation, Torsion, and Forci-pressure. I have given each one a fair trial and now offer my ultimate conclusions. It is only fair to add, however, that it is cauterisation and forci-pressure that I have had the most experience with. Having said that, I will first dispose of pressure, as employed by the wooden antiseptic clams, and torsion.

Concerning Pressure. - I have before said that it is safe and reliable. It may be performed with the patient standing or recumbent, and there is no hæmorrhage into the scrotum. Its only disadvantage, 
and it is a formidable one to a practitioner with a busy practice, is that it necessitates a second journey to remove the clams. For that reason it has not had an extensive trial from me.

Torsion I have employed some few times, and must say that in every instance it gave satisfaction. It is on purely theoretical grounds that I have really not given it a fair trial. I do not think that limited torsion, as we apply it (simply grasping the whole of the cord in one pair of clams and twisting it off in its entirety with a second), can be a safe and surgical method of stopping the hæmorrhage. It still remains for some one with a long list of cases spread over a period of some years to convince me to the contrary.

Forci-Pressure, as performed with the various instruments I have indicated, I can speak of with more certainty. We have used it in our practice from I 893 until quite recently. The first instrument used was the original one of Blake. For some two or three years we had no great cause for complaint. Then, as time went on, and the animals operated on began to arrive at the ages of two, three, and four years, we (I am quoting my father's cases, now, in addition to my own) received complaints from various owners that the colts we cut were a great deal thicker in the scrotum than they should be. The complaints even went so far as to say the animals appeared, some months after they were cut, as though they had never been operated on at all, and that their appearance was such as to seriously affect their sale as geldings.

Putting that on one side, a careful revision of our cases pointed to several instances where hæmorrhage was, to say the least of it, dangerously excessive. Not that ever a colt died from it, but it was sufficient to cause anxiety and alarm. It was also noticed that cases of abscesses appearing in the scrotum (abscesses of a large size) were a great deal too frequent. These abscesses were of sufficient size and gravity to render the patients' condition alarming. Even recovery from imminent danger was followed by a long period of weakness, debility, and general lassitude. Always, no matter how careful the operator may be, there is haemorrhage, varying from a few droplets to a stream of some few minutes' duration, from the cord. This collects in the scrotum, and forms an excellent culture-ground for every kind of putrefactive and pathogenic bacterium.

The other side of the picture is undoubtedly attractive. I refer to those cases in which only a few droplets of blood are spilled and the wound heals by first intention. When that happens one is sorely tempted, in face of all other reverses, to still adopt a method that is likely to bring about such a result. After so short a period as three or four days it requires a rather close inspection to see that the animal has been recently castrated. No unsightly swellings of the scrotum and no disfiguring effusions of the sheath are present, and the owner and operator alike are charmed. Could we but ensure this happy state of affairs occurring in even 80 or 90 per cent. of our cases, then this method would be the one par excellence.

$\mathrm{M}_{y}$ experience, however, goes to show that these cases are the rare exceptions, and that in the majority of animals operated on with these emasculators hæmorrhage in a greater or lesser degree may be looked for. A few moments' reflection will show that the principal artery may be so surrounded with the enveloping tissues of the cord 
as to render its perfect crushing between the blades of the instrument (the very act that should stop the hæmorrhage) unlikely. The younger animals, those only a year old, are the ones that give the best results - a positive proof, to my mind, of the inadaptibility of these instruments for the purpose of checking hæmorrhage from an important vessel.

All the instruments mentioned, with the exception of Webb's, I have given a fair trial, and the conclusions I have arrived at are as I have said. The methods of all, to me, savour far too much of, "You press the handles and Providence will do the rest."

The Operation by Actual Cautery may be dismissed in a very few words. "Barbarous," some will say. No doubt it appears so, but that it is really more painful than other operations we have no means of proving. That it is safe and effectual every one is agreed. I hav'e never yet heard a single voice to the contrary. Why, then, continue to use methods that a short trial has shown to be unreliable and dangerous to the animal's life?

My position (and I expect others are in the same boat) is this. I am perfectly convinced, from actual experience, that of all methods now in vogue the operations by wooden antiseptic clams, and by the clams and hot iron, are the two most safe. "Granted," someone may exclaim, "but the clams require a second journey to be made in order to remove them." "Just so," we answer, and the majority of us leave them alone, and return after trials of other tools to the old-fashioned, barbarous-looking clams and irons, inwardly praying for some other method to turn up neater in appearance, less revolting to the uninitiated, but withal equally safe for the colt. Until that happens I for one shall use the irons.

Should the Operation be performed with the Colt standing? - In all the controversy this question has called forth, I have until now refrained from saying a word. It seems to me that the answer to a very great extent is not for us to give. Many owners insist on having it so done. "Either," they say, "you cut the colt so, or someone else must." In face of that I have had to perform the operation whether or not. That it is more dangerous to the operator than the casting I am fully assured. That it is less dangerous to the colt I am not so certain of.

A talk with any broad-minded standing operator will elicit the fact that they always run one risk. A colt may be the subject of scrotal hernia to such a slight extent as to be unnoticeable. Liberation of the testicle and its removal is rapidly followed by descent of the intestines, and before side-lines can be adjusted and the animal thrown he may have received such injuries as to render his case hopeless. That, to my mind, constitutes the greatest feature of the unsurgical aspect of the operation.

It was brought forcibly to my notice while operating in the recumbent position in the summer of 1898 . The scrotum of this animal to all outward appearance showed nothing abnormal; neither had the owner or the men in charge perceived anything at all out of the ordinary. Nevertheless, intestines to the quantity that would have filled an ordinary-sized bucket quickly followed the testicle. They were washed with the bucket of carbolic solution already at hand, and carefully returned to the abdomen. The scrotal wound was sutured, and the animal made a good recovery. Had he been on his feet, I 
have not the slightest hesitation in saying that the result would have been exactly the reverse. I state emphatically that the standing operation is not surgical. You are not prepared for emergencies, as every good surgeon should be. You are working in a state of nervous anxiety an operator should never be in. I shall never again operate on a colt in the standing position without the case I have quoted being uppermost in my mind at the time. That is not a state of feeling conducive to good workmanship. I may perhaps be nervous, but I can confidently assert that it is not all on my own account; part of it is for the colt, and that is sufficient reason for me to oppose the standing method of operating whenever an opportunity occurs.

When wishing, for these reasons, to avoid the operation and still retain my client, I have found this to be the best means. Readily agree to his wish to have his colt castrated in this manner. Assure him that you are quite able to do it, and politely intimate that it is not the slightest trouble. Having done this, next carefully explain to him your grounds for not advising it, always adding that of course you will do it if he wishes, and nine times out of ten you will then castrate the colt in the way you yourself prefer.

To sum up, I think the reader will see that my conclusions are as follows :-

I. That of the only two really safe methods the clam and hot iron is eventually the most convenient.

2. That the standing operation is dangerous alike to animal and operator, and not, therefore, to be advised, though necessity may sometimes compel its adoption.

3. That all emasculators are risky, owing to the blood they leave collected in the scrotum.

In conclusion, I beg to state that none of this is written with the smallest intention of creating correspondence. I have never been bigoted. I have in practice given many methods a fair trial. I simply wish now to add my experience to that of others.

These remarks and conclusions I have been for some time maturing, but have never before put to paper. They are my earnest convictions, and as such I leave them.

\title{
THE USE OF THE FLESH OF TUBERCULOUS ANIMALS. ${ }^{1}$
}

\author{
By Dr D. A. DE JONG, Leiden.
}

MANY Congresses have already discussed the question of the use of the flesh of tuberculous animals, but without arriving at any important practical results. It appears to me that it must always be very difficult for an International Congress to arrive at conclusions that can serve for the guidance of practical veterinary meat inspectors of different countries in the discharge of their duties.

I therefore at first hesitated to undertake the writing of a paper on the subject. And if I have nevertheless undertaken the task, that

1 Translation of a Paper contributed to the Proceerlings of the Seventh International Veterinary Congress. 